\title{
NIKOLAJ LÜBECKER, Mallarmé's instruments: the production of the Individu-Livre
}

\section{Lara Pasquini Perrott}

\section{(2) OpenEdition}

\section{Journals}

\section{Édition électronique}

URL : https://journals.openedition.org/studifrancesi/32133

DOI : $10.4000 /$ studifrancesi.32133

ISSN : 2427-5856

Éditeur

Rosenberg \& Sellier

\section{Édition imprimée}

Date de publication : 1 août 2020

Pagination : 433

ISSN : 0039-2944

\section{Référence électronique}

Lara Pasquini Perrott, « NIKOLAJ LÜBECKER, Mallarmé's instruments: the production of the Individu-Livre », Studi Francesi [En ligne], 191 (LXIV | II) | 2020, mis en ligne le 01 septembre 2020, consulté le 18 septembre 2021. URL : http://journals.openedition.org/studifrancesi/32133 ; DOI : https://doi.org/ 10.4000/studifrancesi.32133

Ce document a été généré automatiquement le 18 septembre 2021.

\section{(c) (i) (9)}

Studi Francesi è distribuita con Licenza Creative Commons Attribuzione - Non commerciale - Non opere derivate 4.0 Internazionale. 


\title{
NIKOLAJ LÜBECKER, Mallarmé's instruments: the production of the Individu-Livre
}

\author{
Lara Pasquini Perrott
}

\section{RÉFÉRENCE}

NIKOLAJ LÜBECKER, Mallarmé's instruments: the production of the Individu-Livre, “French

Studies" 3, vol. LXXIII, July 2019, pp. 367-383.

1 Nikolaj Lübecker dans son article remet en question l'interprétation du terme instrument dans l'œuvre mallarméenne. Il souligne que Stéphane Mallarmé n'opère pas une forte distinction entre le sens musical et technique du mot instrument, en ajoutant que la vision mallarméenne de la littérature pourrait être définie comme instrumentale et spirituelle. Selon lui l'instrument n'est en réalité que le Livre conçu comme instrument spirituel.

2 L'étude de Lübecker s'évertue à démontrer que l'idée mallarméenne du livre, en tant qu'instrument spirituel, pourrait se lier à une conception écologique de la subjectivité qui anticiperait les théories contemporaines des liens entre les êtres humains, les processus techniques et l'environnement. En effet, il tend à désigner Mallarmé comme écrivain écologique qui, à travers l'œuvre fictive, faciliterait l'harmonie des hommes et de l'environnement. Pour ce faire, il articule son argumentaire en trois sections. En premier lieu, il analyse les théories spéculatives concernant le livre, en deuxième lieu prend en examen des pratiques d'écriture et de lecture et en dernier lieu s'appuie sur la mise en avant des théories philosophiques de Gilbert Simondon pour expliquer ce que Mallarmé entendait quant à sa définition d'instrument spirituel, pour enfin étudier l'interprétation de la subjectivité justifiant cette vision de l'instrument. Lübecker sollicite Mallarmé et sa vision - «le monde est fait pour aboutir à un beau livre»-, analysant le rôle social du livre et de sa beauté linguistique. En effet, plusieurs passages 
dans l'œuvre de Mallarmé soulignent la fonction socio-politique du livre. Sauvegarde (1895) fait figure de l'une des plus célèbres références où l'auteur rappelle à ses lecteurs l'importance d'être politique. La deuxième argumentation se concentre sur le livre comme une pratique. La notion de pratique apparait à plusieurs occasions dans ses ouvrages, en particulier quand il fait référence à la lecture. Enfin, la dernière partie s'achève sur la production de l'individu-livre qui explicite le fait qu'il n'existerait pas d'opposition entre la culture et la technique. L'art deviendrait donc le trait d'union entre ces deux mondes. L'article s'achève sur l'idée porteuse selon laquelle Mallarmé établit que l'instrumentalité n'aurait pas de lien nécessaire avec la réification et l'objectivation; ou autrement dit que la pratique du livre instrumental et spirituel aboutit à un individu-livre. Stéphane Mallarmé explore ainsi les questions contemporaines relatives à la signification de l'«Environnement», aux formes d'individualisation qui émergent de nos différents instruments et enfin, à la manière dont une «action restreinte» pourrait aider à produire de nouveaux systèmes. 